\title{
Effect of sorafenib combined with cytostatic agents on hepatoblastoma cell lines and xenografts
}

\author{
C Eicher ${ }^{*}, 1,4$, A Dewerth $^{1,4}$, J Thomale ${ }^{2}$, V Ellerkamp ${ }^{1}$, S Hildenbrand ${ }^{3}$, S W Warmann ${ }^{1}$, J Fuchs ${ }^{1}$ and
} S Armeanu-Ebinger ${ }^{1}$

${ }^{1}$ Department of Pediatric Surgery and Urology, University Children's Hospital, Hoppe-Seyler-Strasse 3, 72076 Tuebingen, Germany; ${ }^{2}$ Institute of Cell Biology, University of Essen Medical School, Hufelandstrasse 55, 45122 Essen, Germany; ${ }^{3}$ Institute of Occupational and Social Medicine and Health Services Research, University Hospital Tuebingen, Wilhelmstrasse 27, 72074 Tuebingen, Germany

Background: Sorafenib has recently been shown to reduce tumour growth in hepatoblastoma (HB) xenografts. The effect of a combined administration with cytostatic agents was now investigated.

Methods: Cell viability after treatment with sorafenib and different cytostatic agents was evaluated in two HB cell lines ( $\mathrm{HUH} 6$ and HepT1) using MTT assay. ERK signalling was investigated by western blot, NOXA expression by rt-PCR, and formation of DNA adducts using immunocytology. NMRI mice bearing subcutaneous HUH6-derived tumours were treated with sorafenib alone or in combination with cisplatin. Tumour progression, viability, apoptosis, and vascularisation were monitored by tumour volume, AFP levels, TUNEL assay, and CD31 immunostaining, respectively.

Results: The combination of sorafenib and cisplatin led to a remarkable decrease in cell viability. The cisplatin-induced enhanced ERK1/2 activation, but not NOXA expression and the formation of DNA adducts was partly abrogated by sorafenib. In HB xenografts, both, sorafenib and alternated application of sorafenib and cisplatin significantly reduced tumour growth $(P<0.05)$. Levels of AFP were lower in both treated groups $(P=0.08)$. Relative apoptotic areas were increased $(P=0.003)$. Mean vascular density was the lowest in the sorafenib/CDDP group $(P=0.02)$.

Conclusion: The combination of sorafenib with cisplatin might be a promising treatment option for high risk or recurrent HB.

The multikinase inhibitor sorafenib (BAY 43-9006) has been shown to exert a potent tumour growth inhibition in vitro for various types of cancer (Wilhelm et al, 2008). While sorafenib is established in the treatment of advanced HCC in adults, little is known about the impact of sorafenib in childhood liver cancer (Llovet et al, 2008; Schmid et al, 2012). Preliminary data indicate a possible role for sorafenib in paediatric HCC (Schmid et al, 2012). In xenotransplanted hepatoblastoma (HB), treatment with sorafenib recently evidenced a potent inhibition of tumour growth and angiogenesis (Eicher et al, 2012).
Hepatoblastoma is the most common liver tumour in children with a 3 -year overall survival of $95 \%$ in the standard risk group. However, survival of children with high risk or recurrent $\mathrm{HB}$ remains poor (3-year survival 67\%) (Zsiros et al, 2010).

The impact of sorafenib is based on its dual action. Within tumour cells, it reduces tumour cell proliferation by blocking seronine/threonine kinases and induces apoptosis by reduction of the anti-apoptotic protein Mcl-1 (Wilhelm et al, 2004). Furthermore, sorafenib acts in an anti-angiogeneic manner by inhibiting receptor tyrosine kinases (RTKs), including endothelial growth

\footnotetext{
*Correspondence: Dr C Eicher, E-mail: carmen.eicher@med.uni-tuebingen.de

${ }^{4}$ These authors contributed equally to this work.
} 
factor receptor VEGFR-1, VEGFR-2, VEGFR-3, platelet-derived growth factor receptor (PDGFR), and stem cell factor receptor (KIT) (Wilhelm et al, 2008). Both effects are transduced by the ERK1/2 (extracellular signal-regulated kinase) signalling pathway. An increased phospho-ERK1/2 activity in patients with HCC has been correlated with a good response to sorafenib (Abou-Alfa et al, 2006).

Since chemotherapeutic agents are firmly established in treatment study protocols of $\mathrm{HB}$, we investigated the impact of sorafenib in combination with different cytostatic agents on $\mathrm{HB}$ cell lines and in a xenotransplanted HB mouse model.

\section{MATERIALS AND METHODS}

Cell culture. Two continuous HB cell lines were used for all experiments. The cell line HUH6 was derived from a mixed HB (Doi, 1976). The HepT1 cell line originated from a multifocal embryonal HB (Pietsch et al, 1996). Cells were grown in Dulbecco's modified Eagle's medium (DMEM; Biochrom, Berlin, Germany) supplemented with $10 \%$ fetal calf serum (FCS) and $1 \%$ L-glutamine on plastic culture dishes (Greiner, Essen, Germany). Cells were maintained in a humidified atmosphere of $95 \%$ air and $5 \% \mathrm{CO}_{2}$ at $37^{\circ} \mathrm{C}$ and were proven to be Mycoplasma negative.

Preparation of sorafenib. BAY 43-9006 POWD 50 MG TOS 003 SOL (sorafenib) was kindly provided by Bayer HealthCare (Berlin, Germany) and used for all experiments. For in vitro studies, sorafenib was dissolved in 100\% DMSO and diluted in DMEM to the required concentration with a final DMSO concentration of $0.1 \%$. For animal studies, BAY 54-9085 was dissolved in a Cremophor EL/Ethanol (50:50, Cremophor EL; Sigma, Munich, Germany) solution at 10-fold of the highest dose and stored at $4{ }^{\circ} \mathrm{C}$. This stock solution was freshly prepared every 3 days. Through dilution in glucose $50 \%$, solutions with the final doses were prepared immediately before administration.

Cell viability. Cells were cultured in 96-well plates (Becton Dickinson $\mathrm{GmbH}$, Heidelberg, Germany) as described above. $5 \times 10^{3}$ HUH6 cells and $2 \times 10^{4}$ HepT 1 cells were seeded in $100 \mu \mathrm{l}$ culture medium. Cells were treated with CDDP (HUH6 + HepT1: 0.15-10 $\mathrm{g} \mathrm{ml}^{-1}$ ), Doxorubicin (HUH6: $0.009-0.6 \mu \mathrm{g} \mathrm{ml}^{-1}$; HepT1: $\quad 0.078-5.0 \mu \mathrm{g} \mathrm{ml}^{-1}$ ), Irinotecan (HUH6 + HepT1: 0.78-50 $\mu \mathrm{g} \mathrm{ml}^{-1}$ ), Topotecan (HUH6 + HepT1: 0.006-0.4 $\mu \mathrm{g} \mathrm{ml}^{-1}$ ) with and without sorafenib $(1,2 \mu \mathrm{M})$ for $72 \mathrm{~h}$. Drug diluents were prepared shortly before administration. Cell viability was assessed by MTT (3-(4.5-dimethylthiazol-2-yl)-2.5-diphenyl-tetrazoliumbromide) assay (Sigma-Aldrich, Munich, Germany) as previously described (Eicher et al, 2012). Absorption at $570 \mathrm{~nm}$ was measured using a Milena Kinetic Analyzer (DPC Bierman, Bad Nauheim, Germany). All assays were performed in triplicates. Cell viability was normalised to control cultures.

Western blot analysis. Western blot analyses were carried out as previously described. P44/42 (ERK1/2) mouse mAb (\#4696) and phospho-p44/42 (pERK1/2; Thr202/Tyr204) rabbit mAb were used in a concentration of 1:2000 (\#9101, both from Cell Signaling Technology Inc., Danvers, MA, USA). Glyceraldehyde-3-phosphate dehydrogenase (GAPDH) served as control for protein loading (1:200, sc-25778; Santa Cruz, Heidelberg, Germany). HRP-labelled secondary antibodies (GE Healthcare Europe GmbH, Freiburg, Germany) served for visualisation by chemiluminescence (Roti Lumin, Carl Roth, Karlsruhe, Germany). Densitometric analysis was carried out using AlphaDigiDoc software (Biozym Scientific, Oldendorf, Germany).

Quantitative real-time reverse transcription PCR. Hepatoblastoma cell lines HUH6 $\left(3 \times 10^{5}\right.$ cells $)$ and HepT1 $\left(4 \times 10^{5}\right.$ cells $)$ were treated with $\operatorname{CDDP}\left(2 \mu \mathrm{g} \mathrm{ml}^{-1}\right)$, Sorafenib $(3 \mu \mathrm{M})$, or a combination of both for $72 \mathrm{~h}$ before RNA isolation. Total RNA was then isolated using the RNeasy Mini Kit in a QIAcube according to manufacturer's instructions (Qiagen, Hilden, Germany). Reverse transcription was performed using a high capacity cDNA archive kit and $1 \mu \mathrm{g}$ RNA into $20 \mu \mathrm{l}$ assay (Applied Biosystems, Darmstadt, Germany). The gene expression level of NOXA was measured by TaqMan detection via quantitative real-time reverse transcription PCR, using the primer NOXA (PMAIP1, HP214062, sense 5'-CTGGAAGTCGAGTGTGCTACTC-3', antisense 5' ${ }^{\prime}$-TGAA GGAGTCCCCTCATGCAAG-3'; Origene, Rockville, MD, USA). Glyceraldehyde-3-phosphate dehydrogenase (Hs99999905_m1; Applied Biosystems) served as control.

The reactions were performed in MicroAmp optical 96-well reaction plates (Applied Biosystems) and incubated for $2 \mathrm{~min}$ at $50^{\circ} \mathrm{C}$ for 1 cycle, for $10 \mathrm{~min}$ at $95^{\circ} \mathrm{C}$ for $1 \mathrm{cycle}$, for $15 \mathrm{~s}$ at $95^{\circ} \mathrm{C}$ for 1 cycle and for $1 \mathrm{~min}$ at $60^{\circ} \mathrm{C}$ for 40 cycles using CFX96 Real-Time System (Bio-Rad Laboratories, Munich, Germany). Relative expression levels were calculated using the $\Delta$ threshold cycle method $(\triangle \mathrm{CT})$ with GAPDH as control. Differences in gene expression were calculated by the $\Delta \Delta$ threshold cycle method $(\triangle \Delta \mathrm{CT})$ using the corresponding untreated culture as reference sample.

CDDP uptake. $10^{6} \mathrm{HUH} 6$ cells were incubated with $100 \mathrm{ng} \mathrm{ml}^{-1}$ CDDP or $100 \mathrm{ng} \mathrm{ml}^{-1} \mathrm{CDDP}$ and $3 \mu \mathrm{M}$ sorafenib for $24 \mathrm{~h}$. Two experiments were carried out in triplicates.

Cells were trypsinised with $0.2 \%$ Typsin (DMEM; Biochrom), counted, homogenised by ultrasound for $20 \mathrm{~s}$ and stored until measurement at $-80{ }^{\circ} \mathrm{C}$. For analysis, samples were brought to room temperature in the dark and diluted 5-10 min before measurement.

Platinum concentration in cell suspension was assessed in duplicates by a GFAAS (graphite furnace atomic absorption spectrometry) system (Unicam M Series SOLAAR AA Spectrometer, Thermo Fisher Scientific GmbH, Dreieich, Germany). Absorbance of platinum was measured at $265.9 \mathrm{~nm}$ with Zeeman background correction in the calibration modus using standard addition.

Samples or standard platin solutions (Platinum Standard for AAS, TraceCERT, FLUKA, Seelze, Germany) were diluted with 2\% nitric acid (JT Baker, Phillipsburg, Canada) in $0.02 \%$ Triton X-100 (Merck, Darmstadt, Germany) prior measurement. The recovery rate of a platinum standard of $50 \mathrm{ng} \mathrm{ml}^{-1}$ ranged from $91.41 \%$ to 109.87\% (mean: $98.44 \%$ ). To estimate the precision, five samples of cell suspension were spiked with standard $\left(50 \mathrm{ng} \mathrm{ml}^{-1}\right)$ and measured on two different days. The standard deviation of the results was $3.43 \mathrm{ng} \mathrm{ml}^{-1}$ and the relative standard deviation was $6.96 \%$. The limit of detection for platinum in the cell suspension was $2.6-3.3 \mathrm{ng} \mathrm{ml}^{-1}$.

Measurement of Pt-(GpG) intrastrand adducts in DNA. The anti-neoplastic activity of cisplatin is based on the formation of platination products in the nuclear DNA, with the guanineguanine intrastrand crosslink cis- $\mathrm{Pt}\left(\mathrm{NH}_{3}\right) 2 \mathrm{~d}(\mathrm{pGpG})$ [Pt- $\left.(\mathrm{GpG})\right]$ representing $>70 \%$ of total DNA platination.

Plated cells were treated with cisplatin $\left(5,10 \mu \mathrm{g} \mathrm{ml}^{-1}\right)$ and were maintained in that medium for 5 or $10 \mathrm{~h}$. Cells were harvested, washed twice in PBS, resuspended and placed on pre-coated microscopic slides (Superfrost Gold, ThermoFisher). Pt-(GpG) intrastrand crosslinks in the nuclear DNA of individual cells were visualised and measured by an immunocytological assay (ICA) using the Pt-(GpG)-specific antibody 'R-C18' essentially as described (Liedert et al, 2006). Briefly, cells were fixed in methanol followed by alkaline denaturation $(70 \mathrm{mM} \mathrm{NaOH}, 140 \mathrm{mM} \mathrm{NaCl}$ in $40 \%$ methanol, $\left.0{ }^{\circ} \mathrm{C}, 5 \mathrm{~min}\right)$ and sequential proteolytic digestion with pepsin $\left(100 \mu \mathrm{g} \mathrm{ml}^{-1}\right)$ and proteinase $\mathrm{K}\left(50 \mu \mathrm{g} \mathrm{ml}^{-1}\right.$; both from Roche, Grenzach, Germany). After blocking with skim milk, DNA adducts were visualised by indirect immunostaining with 
primary antibody R-C18 and Cy3-rabbit anti-rat IgG secondary antibody (Dianova, Hamburg, Germany). Nuclear DNA was counterstained with DAPI $\left(100 \mu \mathrm{g} \mathrm{ml}^{-1}\right)$. Integrated Cy3- and DAPI-derived fluorescence signals from individual nuclei were measured separately by digital image analysis (ACAS 6.0 Cytometry Analysis System, Ahrens Electronics, Bargteheide, Germany), Cy3 signals were normalised to the corresponding DAPI signals of the same nucleus. Mean values $\pm 95 \%$ confidence intervals of $>100$ cells per sample were calculated and expressed as arbitrary fluorescence units (AFUs).

Animals and xenotransplantation. Xenotransplantation was performed as previously described using 6- to 8-week-old female athymic NMRI-Foxn $1^{\text {nu }}$ mice (Warmann et al, 2003). In total, $0.5 \mathrm{ml}$ HUH6 tumour cell suspension $\left(2-3 \times 10^{6}\right.$ cells $)$ was subcutaneously injected into paravertebral areas. Treatment was initiated when tumours had reached a diameter of $5 \mathrm{~mm}$. The animals were divided into three groups: (1) control, (2) sorafenib and (3) combination of sorafenib with CDDP. Observation time was 25 days. CDDP was applied intraperitoneally (i.p.) in a concentration of $3 \mathrm{mg} \mathrm{kg}^{-1}$ bodyweight on days $1-3$ and 14-16. To avoid a possible interaction, Sorafenib tosylate was administered alternately once a day with a dosage of $30 \mathrm{mg} \mathrm{kg}^{-1}$ bodyweight p.o. on days 4-13 and 17-24. Control animals were left untreated. Tumour growth and serum $\alpha$-fetoprotein (AFP) were monitored to determine treatment efficiency. Tumour volumes of treated and control groups $(V=4 / 3 \pi \times a / 2 \times b / 2 \times c / 2)$ were measured every 5 days. Blood samples were taken from the retrobulbar plexus on days 0 and 25. Levels of AFP were determined by ELISA (DRG Instruments GmbH, Marburg/Lahn, Germany).
On day 25, tumours were explanted and prepared for histological analysis. All animal studies were approved by the local government's ethical authority for animal experiments (Regierungspräsidium Tuebingen, No. CK 1/08 and K 5/09), which are in line with the guidelines for the welfare and use of animals in cancer research (Workman et al, 2010).

TUNEL assay. Apoptosis in explanted tumour tissue was assessed using TUNEL assay (Roche, Mannheim, Germany). Paraffinembedded and formalin-fixed tissue sections were transferred into TUNEL reaction mixture $(50 \mu \mathrm{l} /$ section) containing a terminal deoxynucleotidyl transferase (TdT) and fluorescein-dUTP. Cells positive for apoptosis showed a green fluorescent signal and were visualised by a Zeiss Axio Scope epifluorescence microscope (Carl Zeiss GmbH, Oberkochen, Germany) and AxioVision software 3.1 (Carl Zeiss Vision, Aalen, Germany). For statistical analysis, the area of apoptotic tumour of each section was determined and related to the total area of the section.

Vascularisation. Paraffin-embedded sections were used for immunohistochemical staining against CD31. For each group, three micron sections were cut $(10 \mu \mathrm{m})$ from 4 to 5 different paraffined tumour blocks and mounted onto SuperFrost Plus microscope slides ( $\mathrm{R}$ Langenbrinck, Emmendingen, Germany). Unspecific binding sites were blocked by PBS containing $0.1 \%$ Tween-20 (Sigma-Aldrich) and 1\% goat serum (Dako, Carpinteria, CA, USA). Sections were incubated with monoclonal rat anti-mouse CD31 antibody (1:20; Dianova) overnight. A polyclonal rabbit antirat IgG antibody (1:100 biotin-labelled; Biozol, Eching, Germany) was used as secondary antibody. Avidin-biotin-peroxidase-complex
A

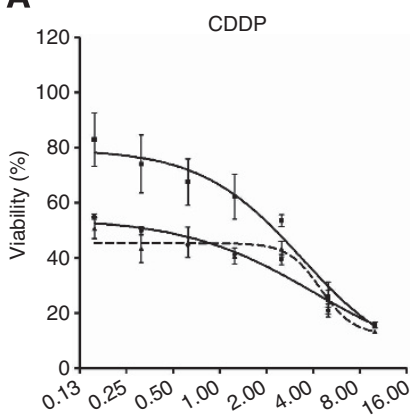

B

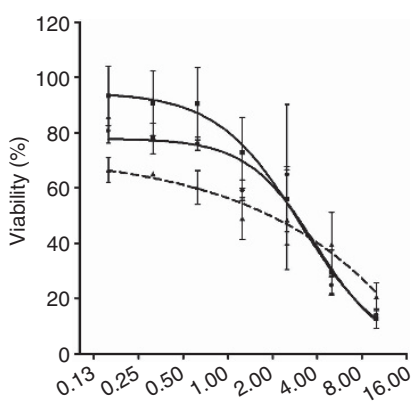

\section{C}

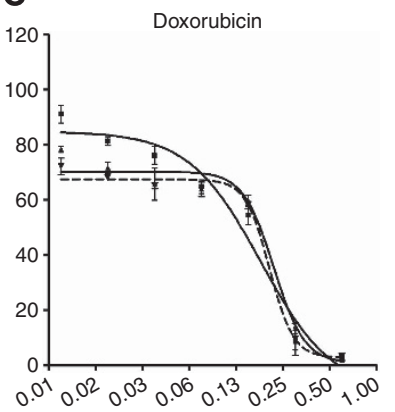

HUH6

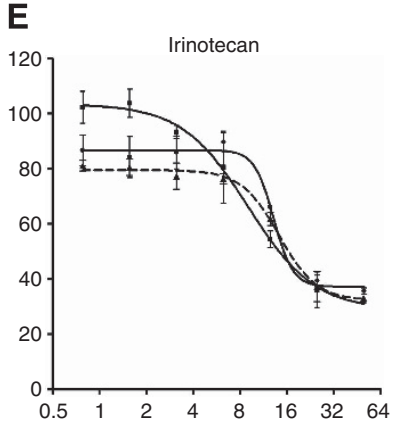

$\left(\mu \mathrm{g} \mathrm{ml}^{-1}\right)$

HepT1

D

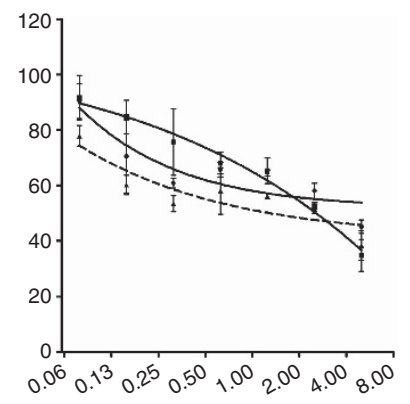

F

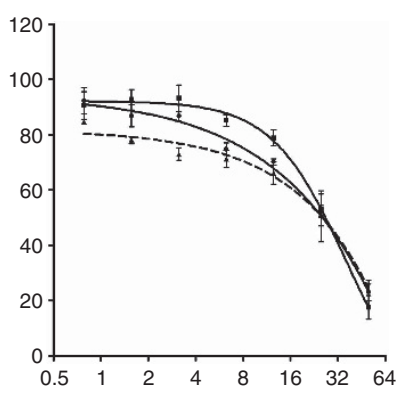

$\left.\mu \mathrm{g} \mathrm{ml}^{-1}\right)$

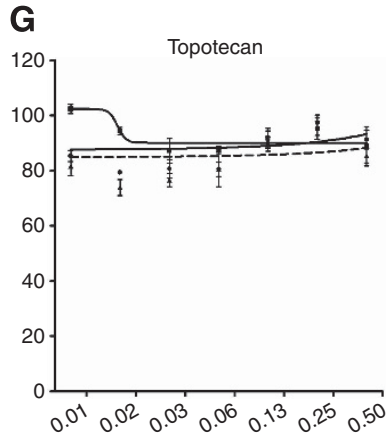

H

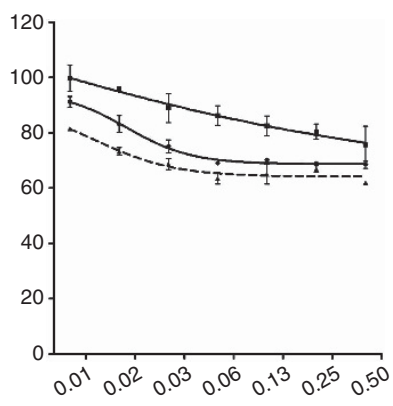

Cytostatic Cytostatic + sorafenib $(1 \mu \mathrm{m})-\mathbf{\Delta}$ - Cytostatic + sorafenib $(2 \mu \mathrm{m})$

Figure 1. Effect of sorafenib and different cytotoxic agents on viability of HB cells. HUH6 and HepT1 were treated with increasing concentrations of CDDP (0,15-10 $\mathrm{g} \mathrm{ml}^{-1}$ (A and B), Doxorubicin (HUH6 (C): 0.009-0.6 $\mu \mathrm{g} \mathrm{ml}^{-1}$; HepT1 (D): 0.078-5.0 $\mu \mathrm{g} \mathrm{ml}^{-1}$ ), |rinotecan (0.78-50 $\mu \mathrm{g} \mathrm{ml}{ }^{-1}$ $(\mathbf{E}$ and $\mathbf{F})$, Topotecan $\left(0.006-0.4 \mu \mathrm{g} \mathrm{ml}^{-1}(\mathbf{G}\right.$ and $\mathbf{H})$ and Sorafenib $(1,2 \mu \mathrm{M})$ for $72 \mathrm{~h}$. Cell viability related to untreated control cultures was determined by MTT assay. Data represent mean \pm s.d. from triplicates. 
(ABC) method was applied using ABC-Kit PK-6100 standard (Linaris, Wertheim, Germany). The peroxidase substrate kit ImmPACT AEC (SK-4205; Linaris) was used for visualisation. Positive endothelial cells were stained red. For nuclear staining, sections were counterstained in Mayer's Haemalaun solution. Sections were then embedded in Dako Fluorescent Mounting Medium (Dako GmbH, Hamburg, Germany) and analysed by inverted microscopy (Axiovert 135; Carl Zeiss, Oberkochen, Germany). For each section, mean vascular density (MVD) was assessed as the number of blood vessels per hyperfield at 10-fold magnification for a minimum of 10 fields and 4 samples per tissue specimen. Two independent examiners performed this quantification. Areas of peripheral connective tissues and necrotic/apoptotic areas were excluded.

Statistical analyses. Cell viability was analysed by one-way ANOVA (GraphPad Prism 4.00; GraphPad Softwares Inc., San Diego, CA, USA). Viability curves were fitted with a sigmoidal dose response function with variable slope and were analysed by twoway ANOVA and Bonferroni-post test. AFP blood levels, relative apoptotic areas and MVD were calculated with two-tail Student's $t$-test. All numeric data are expressed as mean \pm standard deviation or $95 \%$ confidence interval. A value of $P<0.05$ was considered as significant.

\section{RESULTS}

Effect of sorafenib combined with different cytostatic agents on HB cells. The effect of sorafenib with different cytostatic agents on the viability of $\mathrm{HB}$ cells was first monitored by MTT assay. Cell viability in HUH6 and HepT1 cells was decreased by cisplatin (CDDP), doxorubicin, and irinotecan in a dose-dependent manner (Figure 1). Topotecan failed to reduce cell viability. Treatment with CDDP and sorafenib led to an enhanced reduction in both cell lines. Viability in HUH6 cells was reduced from $2 \mu \mathrm{g} \mathrm{ml}^{-1}$ to 0.8 and $1 \mu \mathrm{g} \mathrm{ml}^{-1}$, when combined with sorafenib at 1 and $2 \mu \mathrm{M}$, respectively (Figure 1A). For HepT1, 50\% growth inhibition was assessed with $2.9 \mu \mathrm{g} \mathrm{ml}^{-1} \mathrm{CDDP}$ and was reduced to 2.7 and $2.3 \mu \mathrm{g} \mathrm{ml}^{-1}$ in combination with sorafenib (Figure 1B). With increasing CDDP concentration, the additive effect was abolished in HUH6 as well as in HepT1 cells. The viability curves intersected at concentrations higher than $4 \mu \mathrm{g} \mathrm{ml}^{-1} \mathrm{CDDP}$.

Combining doxorubicin and irinotecan with sorafenib also showed an augmented reduction of cell viability, however, less pronounced than in combination with cisplatin (Figure $1 \mathrm{C}-\mathrm{F}$ ). Using higher cytostatic concentrations, the additive effect was again eliminated. There was no effect of topotecan on HB cells, neither as mono-therapy nor in combination with sorafenib (Figure $1 \mathrm{G}$ and $\mathrm{H}$ ).

Sorafenib reduces pro-apoptotic CDDP signalling via ERK1/2, without alteration of NOXA expression. Effects of sorafenib are known to be transduced by the Raf/MEK/ERK signalling pathway (Gollob et al, 2006), and we recently showed that this pathway might be involved in the sorafenib effect on $\mathrm{HB}$ cells (Eicher et al, 2012). As the combination of CDDP and sorafenib showed the greatest benefit in MTT assay at low CDDP concentrations, we further gained inside the mechanism by western blot analyses. Treatment with sorafenib alone reduced ERK1/2 phosphorylation in HUH6 and to a lesser degree in HepT1 cells (Figure 2). Incubating HUH6 cells with CDDP led to a remarkable activation of ERK1/2 at 0.5 and $2 \mu \mathrm{g} \mathrm{ml}^{-1}$, respectively (Figure 2A). Giving sorafenib and CDDP concomitantly, ERK1/2 phosphorylation was lower compared with control, however, did not reach the effect of sorafenib alone. Combined treatment with sorafenib and CDDP $\left(1,4 \mu \mathrm{g} \mathrm{ml}^{-1}\right)$ showed similar effects in HepT1 cells, yet to a lesser extent (Figure 2B).
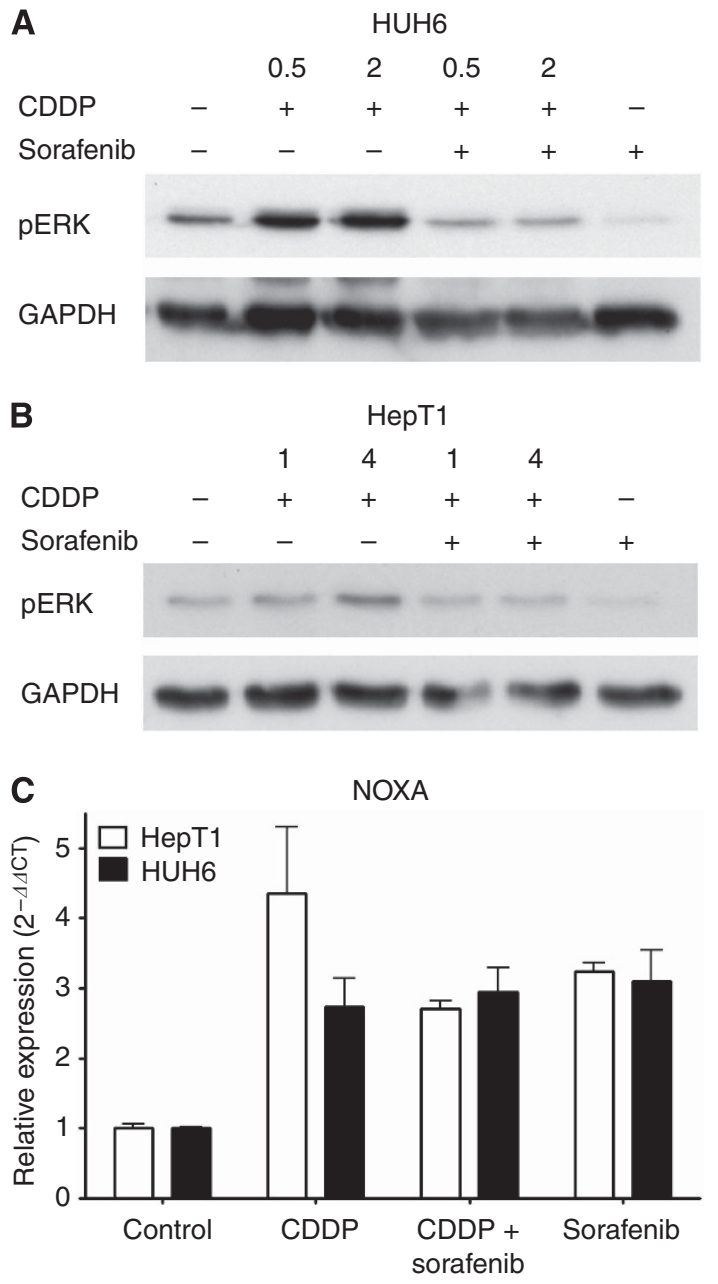

Figure 2. Effect of sorafenib and CPPD on ERK1/2 activation and NOXA expression in HB cells. Western blot analysis of pERK1/2 after treatment with sorafenib $(3 \mu \mathrm{M})$ with or without pre-incubation of CDDP (HUH6: $0.5 ; 2 \mu \mathrm{g} \mathrm{ml}^{-1}$ (A) and HepT1: $1 ; 4 \mu \mathrm{g} \mathrm{ml}^{-1}$ (B)). (C) Expression of NOXA in HB cells using QRT-PCR after treatment with sorafenib $(3 \mu \mathrm{M})$ and $\operatorname{CDDP}\left(2 \mu \mathrm{g} \mathrm{ml}^{-1}\right)$.

Cisplatin was described to induce apoptosis by an ERKdependent upregulation of the BH3-only protein NOXA (Sheridan et al, 2010). Therefore, we next evaluated NOXA expression in HB cells. In controls of both cell lines, NOXA RNA was present (Figure 2C). Treatment with $2 \mu \mathrm{g} \mathrm{ml}^{-1}$ CDDP led to an increased NOXA expression in HUH6 and to a greater extent in HepT1 cells as revealed by qRT-PCR. Sorafenib also caused an increase in NOXA expression in both cell lines, however, to a lesser extent. The effect of the combination of sorafenib and CDDP on NOXA expression was comparable to those of sorafenib alone. In contrast to the reduction of ERK phosphorylation, the CDDPinduced increase in NOXA expression in HUH6 cells was not influenced by adding sorafenib and was diminished about onethird in HepT1 cells.

CDDP uptake and formation of DNA adducts. For human colon cancer cells, an impaired uptake of CDDP was reported caused by sorafenib (Heim et al, 2005). To evaluate the influence of sorafenib in the context of a CDDP uptake in HB cells, the intracellular CDDP concentration was measured using GFAAS assay with a limit of detection for CDDP of $4.0-5.1 \mathrm{ng} \mathrm{ml}^{-1}$. Less than $5 \mathrm{ng}$ CDDP was accumulated in $10^{6} \mathrm{HUH} 6$ cells regardless of treatment with sorafenib. Thus, sorafenib did not significantly change the 

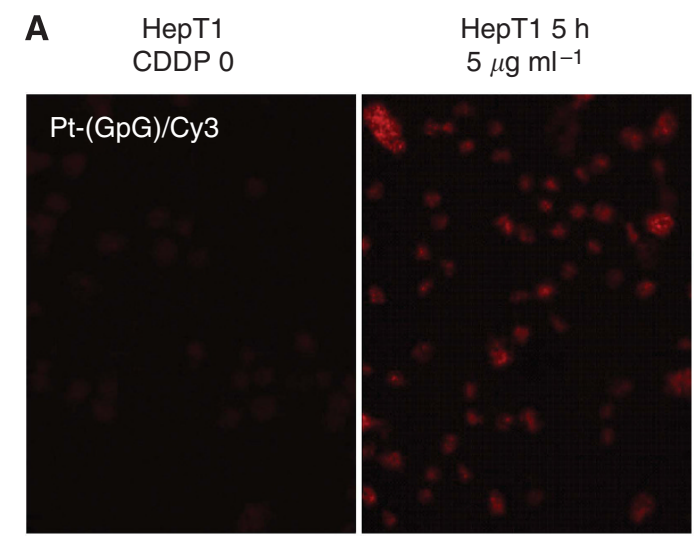

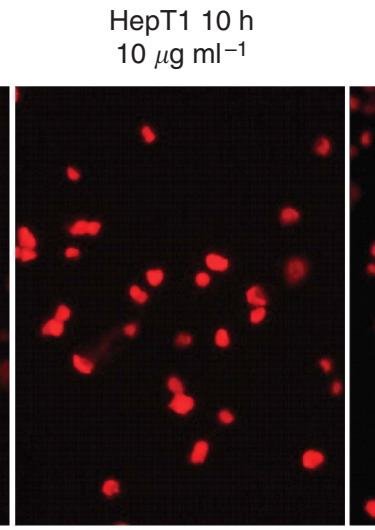

HUH6 $5 \mathrm{~h}$

$5 \mu \mathrm{g} \mathrm{ml}^{-1}$
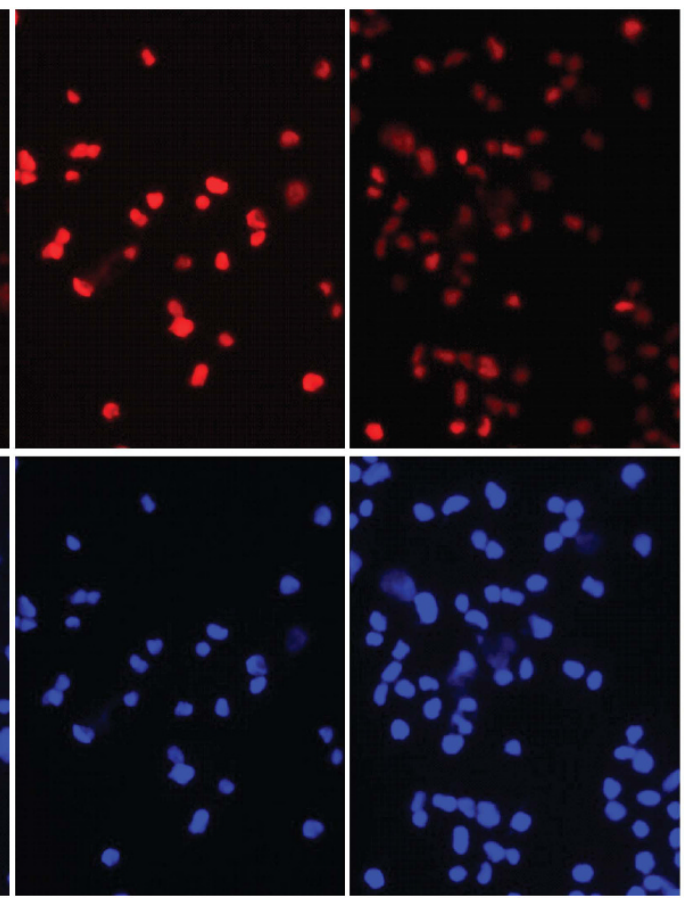

HUH6 $10 \mathrm{~h}$

$10 \mu \mathrm{g} \mathrm{ml}^{-1}$
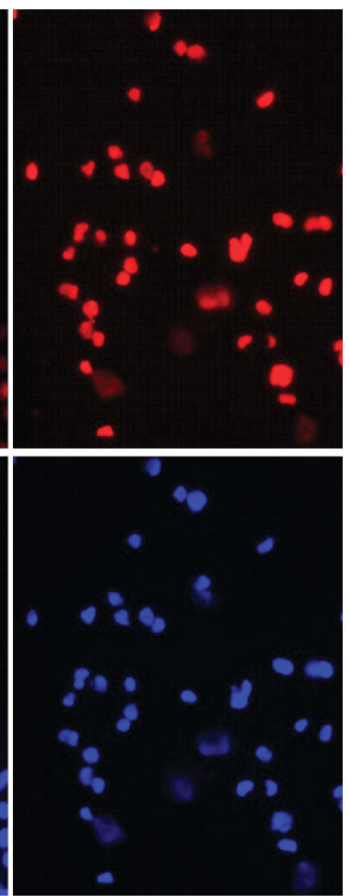

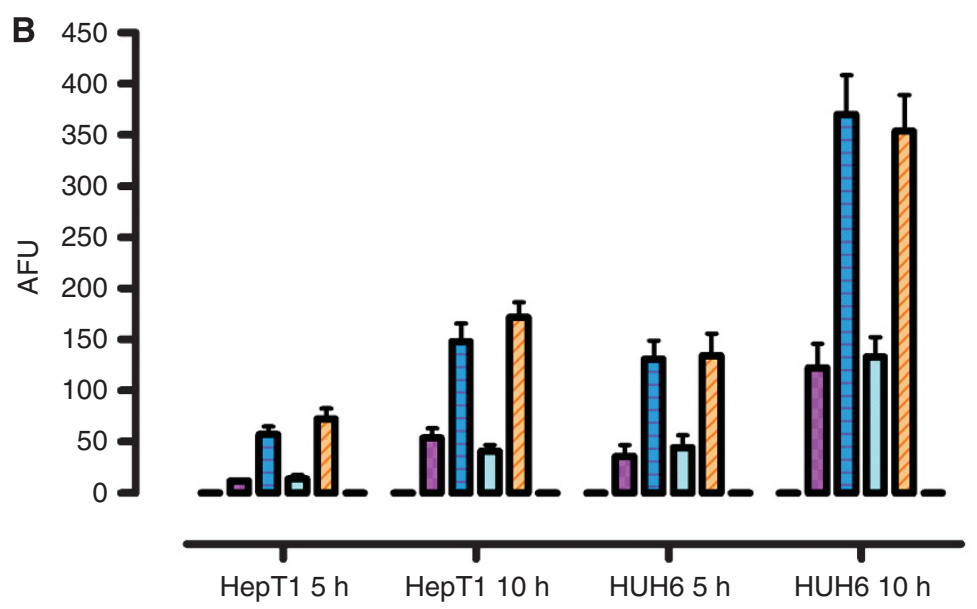

Figure 3. DNA adducts in HB cells treated with CDDP alone and in combination with sorafenib. (A) Formation of Pt-(GpG) adducts was detected by Cy3 immunostaining after incubation of $\operatorname{CDDP}\left(5,10 \mu \mathrm{g} \mathrm{ml}^{-1}\right)$ for 5 or $10 \mathrm{~h}$. Nuclear staining was performed with DAPI. (B) Adduct levels in the nuclear DNA of HB cells were calculated as fluorescence units (AFUs). AFUs were higher in HuH6 compared with HepT1 cells and were not reduced by the combination with sorafenib. Data represent mean \pm s.d. from triplicates.

intracellular CDDP concentration in HUH6 cells as estimated by GFAAS assay (triplicates of two experiments, data not shown).

To further evaluate a possible interfering of sorafenib and cisplatin, the formation of DNA adducts was investigated. Incubating HUH6 and HepT1 cells with 5 and $10 \mu \mathrm{g} \mathrm{ml}^{-1}$ CDDP for 5 or $10 \mathrm{~h}$ revealed a increased formation of Pt-(GpG) adducts detected by immunostaining (Figure $3 \mathrm{~A}$ ). In concordance with the augmented sensitivity to CDDP, the density of DNA adducts was higher in HUH6 cells compared with HepT1 cells and increased in both lines with exposure time and drug concentration. Quantitative evaluation of the Pt-(GpG) levels revealed no influence of sorafenib on the CDDP activity (Figure $3 \mathrm{~B}$ ).

Anti-tumoral effect of sorafenib and CDDP on xenotransplanted HUH6 tumours. For in vivo studies, HUH6 tumours were xenotransplanted subcutaneously in female NMRI-Foxn $1^{\text {nu }}$ mice. Untreated $\mathrm{HB}$ xenografts showed an exponential tumour growth (Figure $4 \mathrm{~A}, n=11$ ). Based on the observed interference of sorafenib and CDDP in western blot analyses, a sequential drug application was performed. Treatment with sorafenib $\left(30 \mathrm{mg} \mathrm{kg}^{-1}\right.$ bw p.o. on days 4-13 and 17-24) led to a significant reduced tumour volume after 25 days compared with control $(P<0.05$ at day $25, n=8)$. Combining both agents in an alternated schedule led to a higher and earlier reduction of tumour volume, getting significant from day 15 of treatment compared with controls $(P<0.05$ at days 15,20 , and $25, n=10)$. In this group, two tumours disappeared beyond the detection limit during treatment.

The direct comparison of the combined treatment with sorafenib revealed a significant difference in relative tumour volume after day 5 of treatment. However, in a multiple comparison analysis, which is shown in Figure 4A, it did not reach significance. 

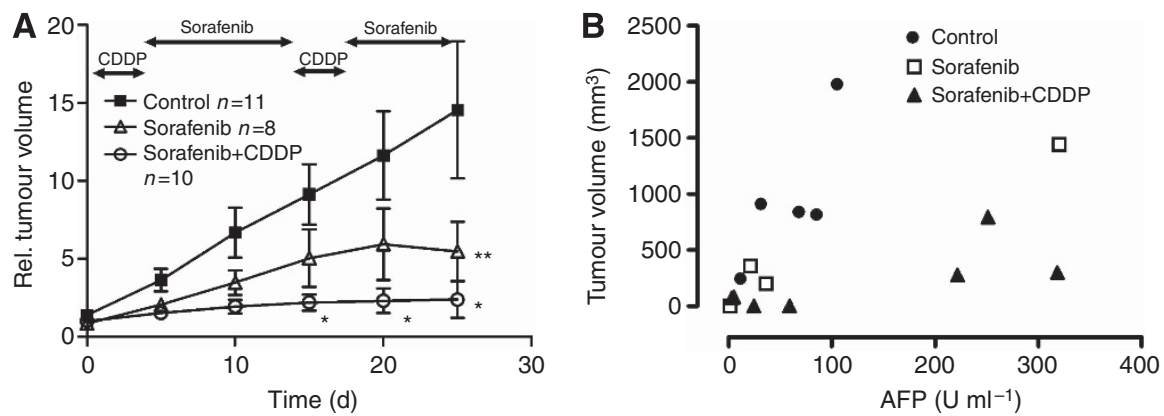

Figure 4. Reduced tumour volume and AFP levels during treatment with sorafenib or sorafenib/CDDP. (A) NMRI mice were treated with CDDP ( $3 \mathrm{mg} \mathrm{kg}^{-1}$ bw on days 1-3 and 14-16) and/or sorafenib (30 $\mathrm{mg} \mathrm{kg}^{-1}$ bw on days 4-13 and 17-24). Relative tumour volume was significantly lower in sorafenib-treated mice after 25 days compared with control. The combination of sorafenib and CDDP showed higher potency reaching statistical significance at day $15\left({ }^{\star}, \star * P<0.05\right.$, Bonferroni post test). Mean and s.e.m. are shown. (B) AFP levels (U ml $\mathrm{m}^{-1}$ ) in relation to tumour volume after 25 days were lower in sorafenib-treated mice. Half of the sorafenib/CDDP treated mice had elevated AFP levels compared with low tumour volumes. Shown are absolute values $(P=N S$, Student's $t$-test).
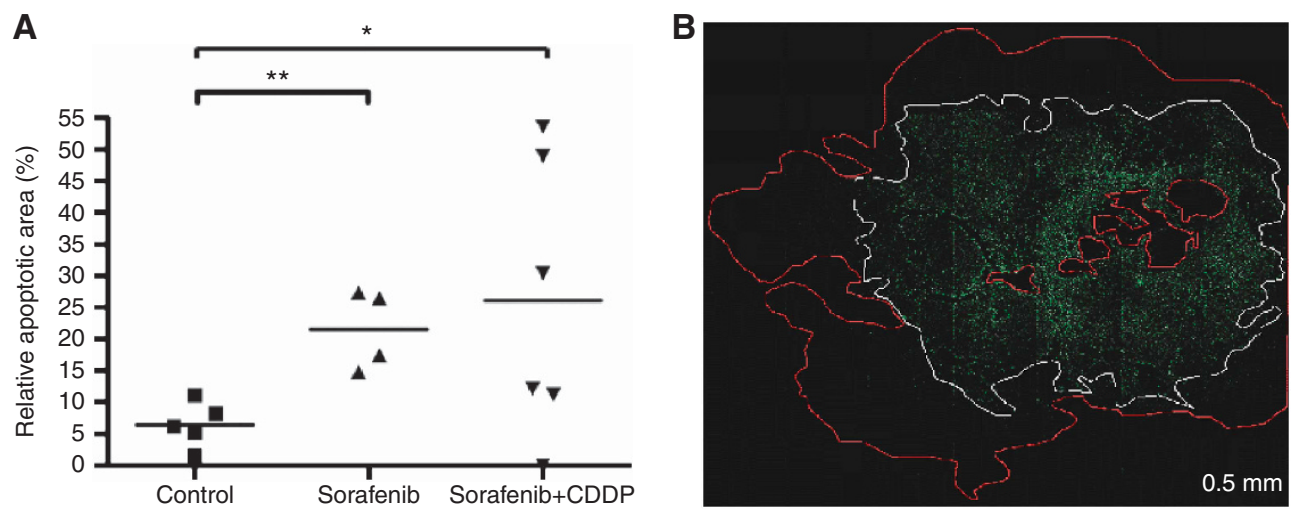

Figure 5. Apoptotic effect. (A) Relative apoptotic areas are increased in sorafenib- $(n=4)$ and sorafenib/CDDP- $(n=6)$ treated mice compared with control $(n=5)$. Means and relative apoptotic area for each animal are shown ( $* * * P=0.03$, student $t$-test). (B) TUNEL assay revealed apoptotic cells containing DNA strand nicks as bright green fluorescent cells (white border) within vital cells (red bordered).

In Figure 4B, tumour volumes and AFP levels at the end of treatment are shown. In control tumours, AFP levels increased proportionally with the tumour volume (slope $13.10 \pm 5.676)$. In contrast, there was no proportional increase in AFP levels to tumour volumes in the combined group (slope $1.544 \pm 0.6424)$. Interestingly, half of the animals treated with sorafenib and CDDP had high AFP concentrations after 25 days, despite low tumour volumes. The AFP at the end of treatment was frequently lower in the sorafenib and sorafenib/CDDP group compared with control mice, but failed to be significant $(P=0.08, n=5)$.

To further describe the anti-tumoral effect of a combined treatment, apoptosis in paraffin-embedded tissue of HB tumour sections was investigated by TUNEL assay. Treatment with sorafenib revealed a significant increase in apoptosis (Figure 5B). Sorafenib combined with CDDP showed no further increase in apoptosis compared with sorafenib alone. Apoptotic areas were significantly higher in tumours of sorafenib-treated mice $(21.5 \pm 3.2 \%)$ as well as in the sorafenib/CDDP group compared with control ( $26.4 \pm 1.6 \% ; P=0.003, n=5$; Figure 5A).

Sorafenib did not only exert an anti-proliferative and proapoptotic effect, but also influenced angiogenesis as revealed by CD31 staining (Figure 6A). Mean vascular density was significantly decreased in sorafenib-treated $(41.5 \pm 7.9)$ as well as in sorafenib/ CDDP-treated mice compared with control (73.2 $\pm 6.9 ; P=0.02$, $n=4$; Figure $6 \mathrm{~B}$ ).

\section{DISCUSSION}

Based on the benefit of sorafenib treatment in adult HCC, a pilot trial by the SIOPEL group combining sorafenib with PLADO in childhood HCC was found to be a promising treatment approach (Schmid et al, 2012). Since epithelial childhood liver tumours differ from adult liver tumours in histology and biology, the anti-tumoral impact of sorafenib cannot be clearly predicted. Recently, the case of a child was reported with recurrent $\mathrm{HB}$ in which sorafenib and bevacizumab, led to disease stabilisation for 3 months (Marsh et al, 2012). We evaluated the impact of sorafenib combined with cytotoxic agents in preclinical HB models.

Combining sorafenib with cisplatin reduced cell viability in HUH6 and HepT1 cells to a higher extent than cisplatin alone. However, beyond the $\mathrm{IC}_{50}$ of both cell lines the additive effect was abolished. Similar effects were seen combining sorafenib with doxorubicin and irinotecan, but to a lower extent. In contrast to previous reports of our group, showing that topotecan reduced tumour growth in three subcutaneously grown human $\mathrm{HB}$ xenografts, it failed to exert an anti-proliferative effect in HB cells in vitro (Warmann et al, 2001). This difference might be explained by the different growth pattern of a solid tumour compared with the single cell culture. The observed interaction of sorafenib and cytostatic agents has been already described and involves uptake of cisplatin into cells (Heim et al, 2005). 
Besides the commonly known effects of cisplatin inducing DNA damage, growing evidence exists that MEK/ERK pathway is a regulator of cisplatin-induced apoptosis (Wang et al, 2000; Schweyer et al, 2004; Amran et al, 2005). In our study, the

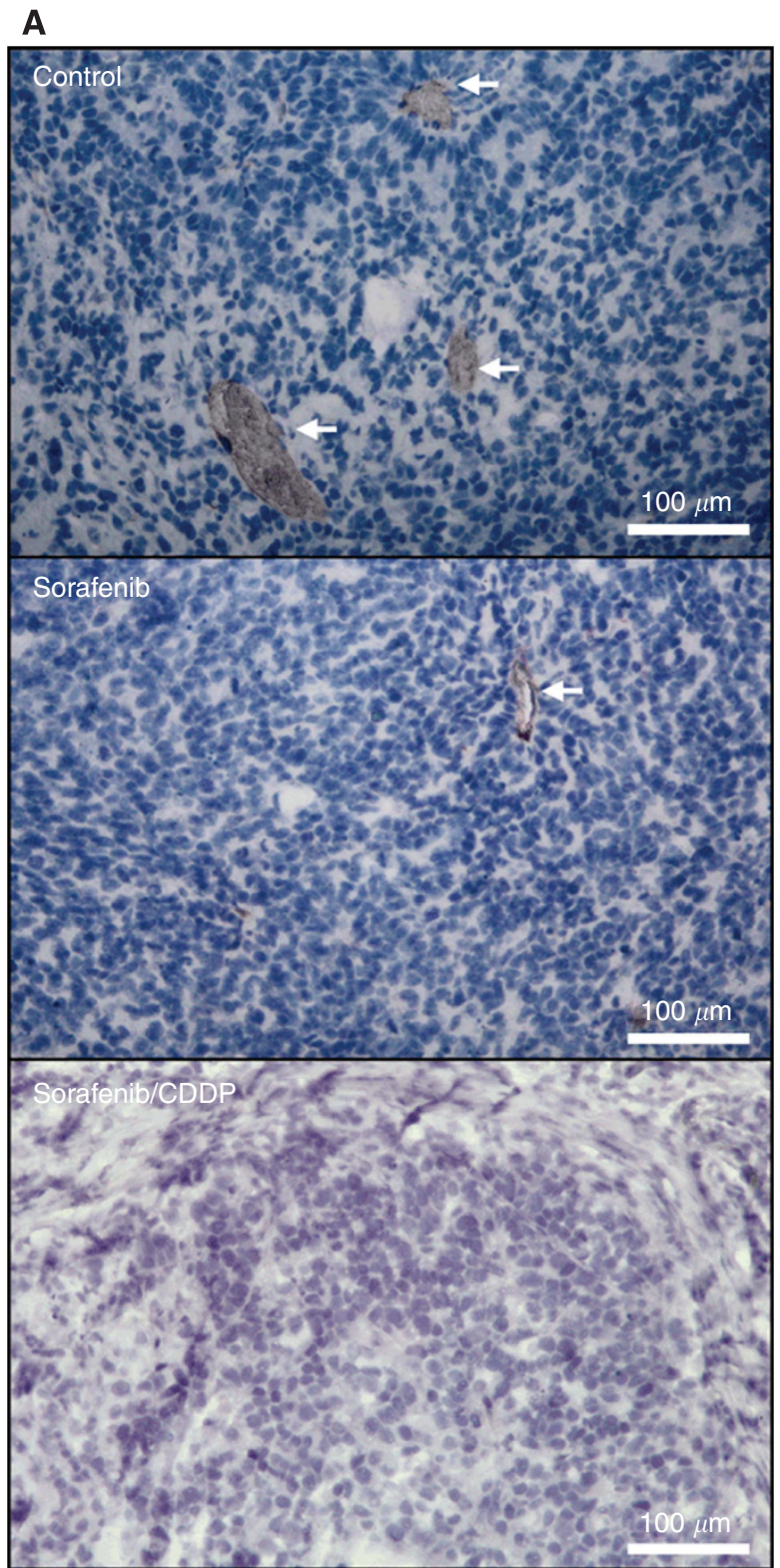

B

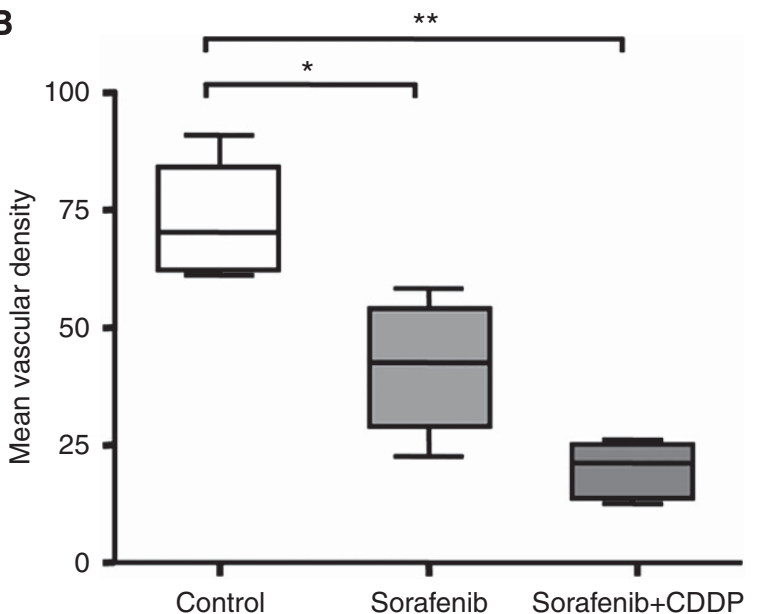

cisplatin-induced ERK activation was higher in HUH6 than in HepT1 cells, and correlated with the higher levels of Pt-(GpG) adducts in DNA and the upregulated expression of NOXA. Thus, cisplatin might induce apoptosis in $\mathrm{HB}$ cells by enhanced NOXA expression via ERK1/2 signalling as shown in HeLa and melanoma cells (Sheridan et al, 2010). As a main target of sorafenib, ERK inhibition may reduce the pro-apoptotic activity of CDDP. Despite reduced ERK activation, through combined treatment, total expression of NOXA was not altered. Hence, induction of apoptosis via NOXA and adduct formation by CDDP seemed to be independent of a reduced phosphorylation of ERK and may act additively to the reduced proliferation caused by sorafenib. Furthermore, other pathways than ERK may be activated inducing NOXA expression by CDDP in HB, such as the calpain pathway in ovarian cancer cells (Al-Bahlani et al, 2011). In contrast to our results, an enhanced ERK reduction has been described for cisplatin and sorafenib in HepG2 cells (Chen et al, 2008).

Sorafenib might attenuate the cisplatin effect by reducing cellular uptake of cisplatin, as reported for other solid tumours (Heim et al, 2005). Uptake studies in HB cells were not successful due to the limit of detection below $5 \mathrm{ng}$ per $10^{6}$ cells. Since we found no significant difference in the adduct levels between cisplatin and the combined treatment, a hindered uptake of cisplatin by sorafenib seems unlikely. Uptake of CDDP and induction of NOXA were not alternated by the combined treatment, and are therefore not responsible for the observed interference in the proliferation assay.

The benefit of cisplatin, in the treatment of $\mathrm{HB}$, has been demonstrated in large clinical studies, and serves as basis in further treatment concepts including sorafenib (Perilongo et al, 2009; Zsiros et al, 2010).

To avoid interference in vivo, sorafenib and cisplatin were applied alternately to NMRI mice bearing subcutaneous HUH6derived tumours. HUH6 cells were used because of the lower tumour incidence of HepT1 xenografts in NMRI mice. We found a strong anti-tumoral effect of sorafenib in vivo, which was comparable to the cisplatin mono-therapy observed in previous studies (Warmann et al, 2005).

Combination of both agents in an alternating administration schedule led to a stronger and earlier reduction of tumour growth. This anti-tumoral action correlated well with the inhibition of tumour angiogenesis, clearly indicating the role of the antiangiogeneic mechanism of sorafenib appearing in tumour tissue.

In the clinical setting, AFP is used as marker for treatment response in $\mathrm{HB}$ as well as indicator for relapse after complete remission. Sorafenib led to a decrease in serum AFP levels, correlating with the reduction of tumour volume. AFP might therefore also serve as molecular marker for monitoring a sorafenib treatment in a clinical setting. However, serum AFP levels are known to exhibit a high variance (Warmann et al, 2005). In our study, some HB tumours showed elevated AFP levels in contrast to low tumour volume, indicating the persistence of viable tumour cells. Similar observations have been made in a variety of human xenografts, characterising growth inhibition of sorafenib as disease stabilisation (Wilhelm et al, 2004).

Our results provide evidence that combination of sorafenib and cisplatin might be an attractive alternative for the treatment of advanced or recurrent HB. Interference between both substances

\footnotetext{
Figure 6. Anti-angiogenic effect. (A) Blood vessels were detected by immunohistological staining of CD31-positive endothelial cells (red) in sorafenib-, sorafenib/CDDP-treated and untreated mice. The blue HE staining denotes $\mathrm{HB}$ cells. (B) Treatment with sorafenib alone and to a higher degree in combination with CDDP resulted in a significant decrease of CD31-positive endothelial cells as estimated by the mean vascular density (MVD). Means, s.d., and confidential intervals (95\%) for each group ( ${ }^{\star}{ }^{\star \star} P=0.02, n=4$, Student's t-test) are shown.
} 
on the level of signal transduction is probable and future efforts seem necessary to reveal such interactions. Main goal will be a better planning of administration of a combined therapy.

\section{ACKNOWLEDGEMENTS}

BAY 43-9006 (sorafenib) was kindly provided by Bayer HealthCare Germany. This study was supported by the research funding programme of the Faculty of Medicine, University of Tuebingen (fortuene 1830-0-0 and 1961-0-0) and by Deutsche Forschungsgemeinschaft, Grant TH 251/5-2 (JT).

\section{CONFLICT OF INTEREST}

The authors declare no conflict of interest.

\section{REFERENCES}

Abou-Alfa GK, Schwartz L, Ricci S, Amadori D, Santoro A, Figer A, De Greve J, Douillard JY, Lathia C, Schwartz B, Taylor I, Moscovici M, Saltz LB (2006) Phase II study of sorafenib in patients with advanced hepatocellular carcinoma. J Clin Oncol 24(26): 4293-4300.

Al-Bahlani S, Fraser M, Wong AY, Sayan BS, Bergeron R, Melino G, Tsang BK (2011) P73 regulates cisplatin-induced apoptosis in ovarian cancer cells via a calcium/calpain-dependent mechanism. Oncogene 30(41): 4219-4230.

Amran D, Sancho P, Fernandez C, Esteban D, Ramos AM, de Blas E, Gomez M, Palacios MA, Aller P (2005) Pharmacological inhibitors of extracellular signal-regulated protein kinases attenuate the apoptotic action of cisplatin in human myeloid leukemia cells via glutathione-independent reduction in intracellular drug accumulation. Biochim Biophys Acta 1743(3): 269-279.

Chen FS, Cui YZ, Luo RC, Wu J, Zhang H (2008) [Coadministration of sorafenib and cisplatin inhibits proliferation of hepatocellular carcinoma HepG2 cells in vitro]. Nan Fang Yi Ke Da Xue Xue Bao 28(9): 1684-1687.

Doi I (1976) Establishment of a cell line and its clonal sublines from a patient with hepatoblastoma. Gann 67(1): 1-10.

Eicher C, Dewerth A, Kirchner B, Warmann SW, Fuchs J, Armeanu-Ebinger S (2012) Treatment effects of the multikinase inhibitor sorafenib on hepatoblastoma cell lines and xenografts in NMRI-Foxn1(nu) mice. Liver Int 32(4): 574-581.

Gollob JA, Wilhelm S, Carter C, Kelley SL (2006) Role of Raf kinase in cancer: therapeutic potential of targeting the Raf/MEK/ERK signal transduction pathway. Semin Oncol 33(4): 392-406.

Heim M, Scharifi M, Zisowsky J, Jaehde U, Voliotis D, Seeber S, Strumberg D (2005) The Raf kinase inhibitor BAY 43-9006 reduces cellular uptake of platinum compounds and cytotoxicity in human colorectal carcinoma cell lines. Anticancer Drugs 16(2): 129-136.

Liedert B, Pluim D, Schellens J, Thomale J (2006) Adduct-specific monoclonal antibodies for the measurement of cisplatin-induced DNA lesions in individual cell nuclei. Nucleic Acids Res 34(6): e47.

Llovet JM, Ricci S, Mazzaferro V, Hilgard P, Gane E, Blanc JF, de Oliveira AC, Santoro A, Raoul JL, Forner A, Schwartz M, Porta C, Zeuzem S, Bolondi L, Greten TF, Galle PR, Seitz JF, Borbath I, Haussinger D, Giannaris T, Shan M, Moscovici M, Voliotis D, Bruix J (2008) Sorafenib in advanced hepatocellular carcinoma. $N$ Engl J Med 359(4): 378-390.

Marsh AM, Lo L, Cohen RA, Feusner JH (2012) Sorafenib and bevacizumab for recurrent metastatic hepatoblastoma: Stable radiographic disease with decreased AFP. Pediatr Blood Cancer 59(5): 939-940.
Perilongo G, Maibach R, Shafford E, Brugieres L, Brock P, Morland B, de Camargo B, Zsiros J, Roebuck D, Zimmermann A, Aronson D, Childs M, Widing E, Laithier V, Plaschkes J, Pritchard J, Scopinaro M, MacKinlay G, Czauderna P (2009) Cisplatin versus cisplatin plus doxorubicin for standard-risk hepatoblastoma. N Engl J Med 361(17): 1662-1670.

Pietsch T, Fonatsch C, Albrecht S, Maschek H, Wolf HK, von Schweinitz D (1996) Characterization of the continuous cell line HepT1 derived from a human hepatoblastoma. Lab Invest 74(4): 809-818.

Schmid I, Haberle B, Albert MH, Corbacioglu S, Frohlich B, Graf N, Kammer B, Kontny U, Leuschner I, Scheel-Walter HG, Scheurlen W, Werner S, Wiesel T, von Schweinitz D (2012) Sorafenib and cisplatin/doxorubicin (PLADO) in pediatric hepatocellular carcinoma. Pediatr Blood Cancer 58(4): 539-544.

Schweyer S, Soruri A, Meschter O, Heintze A, Zschunke F, Miosge N, Thelen P, Schlott T, Radzun HJ, Fayyazi A (2004) Cisplatin-induced apoptosis in human malignant testicular germ cell lines depends on MEK/ERK activation. Br J Cancer 91(3): 589-598.

Sheridan C, Brumatti G, Elgendy M, Brunet M, Martin SJ (2010) An ERK-dependent pathway to Noxa expression regulates apoptosis by platinum-based chemotherapeutic drugs. Oncogene 29(49): 6428-6441.

Wang X, Martindale JL, Holbrook NJ (2000) Requirement for ERK activation in cisplatin-induced apoptosis. J Biol Chem 275(50): 39435-39443.

Warmann S, Gohring G, Teichmann B, Geerlings H, Pietsch T, Fuchs J (2003) $\mathrm{P}$-glycoprotein modulation improves in vitro chemosensitivity in malignant pediatric liver tumors. Anticancer Res 23(6C): 4607-4611.

Warmann SW, Fuchs J, Wilkens L, Gratz KF, von Schweinitz D, Mildenberger H (2001) Successful therapy of subcutaneously growing human hepatoblastoma xenografts with topotecan. Med Pediatr Oncol 37(5): 449-454.

Warmann SW, Heitmann H, Teichmann B, Gratz KF, Ruck P, Hunger M, Fuchs J (2005) Effects of P-glycoprotein modulation on the chemotherapy of xenotransplanted human hepatoblastoma. Pediatr Hematol Oncol 22(5): 373-386.

Wilhelm SM, Adnane L, Newell P, Villanueva A, Llovet JM, Lynch M (2008) Preclinical overview of sorafenib, a multikinase inhibitor that targets both Raf and VEGF and PDGF receptor tyrosine kinase signaling. Mol Cancer Ther 7(10): 3129-3140.

Wilhelm SM, Carter C, Tang L, Wilkie D, McNabola A, Rong H, Chen C, Zhang X, Vincent P, McHugh M, Cao Y, Shujath J, Gawlak S, Eveleigh D, Rowley B, Liu L, Adnane L, Lynch M, Auclair D, Taylor I, Gedrich R, Voznesensky A, Riedl B, Post LE, Bollag G, Trail PA (2004) BAY 43-9006 exhibits broad spectrum oral antitumor activity and targets the RAF/ MEK/ERK pathway and receptor tyrosine kinases involved in tumor progression and angiogenesis. Cancer Res 64(19): 7099-7109.

Workman P, Aboagye EO, Balkwill F, Balmain A, Bruder G, Chaplin DJ, Double JA, Everitt J, Farningham DA, Glennie MJ, Kelland LR, Robinson V, Stratford IJ, Tozer GM, Watson S, Wedge SR, Eccles SA (2010) Guidelines for the welfare and use of animals in cancer research. $\mathrm{Br} J$ Cancer 102(11): 1555-1577.

Zsiros J, Maibach R, Shafford E, Brugieres L, Brock P, Czauderna P, Roebuck D, Childs M, Zimmermann A, Laithier V, Otte JB, de Camargo B, MacKinlay G, Scopinaro M, Aronson D, Plaschkes J, Perilongo G (2010) Successful treatment of childhood high-risk hepatoblastoma with doseintensive multiagent chemotherapy and surgery: final results of the SIOPEL-3HR study. J Clin Oncol 28(15): 2584-2590.

This work is published under the standard license to publish agreement. After 12 months the work will become freely available and the license terms will switch to a Creative Commons AttributionNonCommercial-Share Alike 3.0 Unported License. 